\title{
Availability, Pharmaceutics, Security, Pharmacokinetics, and Pharmacological Activities of Patchouli Alcohol
}

\author{
Guanying Hu, ${ }^{1}$ Cheng Peng, ${ }^{1}$ Xiaofang Xie, ${ }^{1}$ Sanyin Zhang, ${ }^{2}$ and Xiaoyu Cao ${ }^{1}$ \\ ${ }^{1}$ Key Laboratory of Standardization of Chinese Herbal Medicines of the Ministry of Education, \\ Pharmacy College, Chengdu 611173, China \\ ${ }^{2}$ TCM Qi \& Blood Functional Laboratory, College of Basic Medicine, Chengdu University of Traditional Chinese Medicine, \\ Chengdu 611173, China
}

Correspondence should be addressed to Cheng Peng; pengchengchengdu@126.com

Received 20 December 2016; Revised 12 February 2017; Accepted 7 March 2017; Published 21 March 2017

Academic Editor: Juntra Karbwang

Copyright (C) 2017 Guanying Hu et al. This is an open access article distributed under the Creative Commons Attribution License, which permits unrestricted use, distribution, and reproduction in any medium, provided the original work is properly cited.

Patchouli alcohol (PA), a tricyclic sesquiterpene, is one of the critical bioactive ingredients and is mainly isolated from aerial part of Pogostemon cablin (known as guanghuoxiang in China) belonging to Labiatae. So far, PA has been widely applied in perfume industries. This review was written with the use of reliable information published between 1974 and 2016 from libraries and electronic researches including NCKI, PubMed, Reaxys, ACS, ScienceDirect, Springer, and Wiley-Blackwell, aiming at presenting comprehensive outline of security, pharmacokinetics, and bioactivities of PA and at further providing a potential guide in exploring the PA and its use in various medical fields. We found that PA maybe was a low toxic drug that was acquired numerously through vegetable oil isolation and chemical synthesis and its stability and low water dissolution were improved in pharmaceutics. It also possessed specific pharmacokinetic characteristics, such as two-compartment open model, first-order kinetic elimination, and certain biometabolism and biotransformation process, and was shown to have multiple biological activities, that is, immunomodulatory, anti-inflammatory, antioxidative, antitumor, antimicrobial, insecticidal, antiatherogenic, antiemetic, whitening, and sedative activity. However, the systematic evaluations of preparation, pharmaceutics, toxicology, pharmacokinetics, and bioactivities underlying molecular mechanisms of action also required further investigation prior to practices of PA in clinic.

\section{Introduction}

Pogostemonis Herba, the dried aerial part of Pogostemon cablin (Blanco) Benth. (Labiatae), is commonly known as "guanghuoxiang" in Chinese and patchouli in English. It was a long time that Pogostemonis Herba had been used traditionally for the treatment of fatigue, summer heat, nausea, vomit, abdominal distension, and so forth [1]. Patchouli oil is an important essential oil in the perfume industry, keeping a base and lasting character to a fragrance. For characteristic pleasant and long lasting woody and camphoraceous odor, patchouli oil is appreciated and very suitable for the utilization of decorative cosmetics, fragrances, shampoo, toilet soaps, and other toiletries as well as noncosmetic products such as household cleaners and detergents $[2,3]$. Patchouli alcohol $1\left(\mathrm{PA}, \mathrm{C}_{15} \mathrm{H}_{26} \mathrm{O}\right)$, a naturally occurring tricyclic sesquiterpene, is the critically biological active constituent among the patchouli oil extracted from Pogostemon cablin and usually used as a pivotal chemical marker compound for the assessments in quality control of Pogostemonis Herba and patchouli oil in China. However, the practices of PA are blank in medical field, although PA has been demonstrated to possess multibeneficial pharmacological properties, such as immunomodulatory, anti-inflammatory, antioxidative, antitumor, antimicrobial, insecticidal, antiatherogenic, antiemetic, whitening, and sedative activities. To provide further supports and evidences for new drug development and clinical application of PA, a comprehensive review on availability, pharmaceutics, security, pharmacokinetics, and pharmacological properties was executed. The abundant and reliable information on the availability, pharmaceutics, safety, pharmacokinetics, and pharmacological properties was collected via libraries and various electronic search engines 


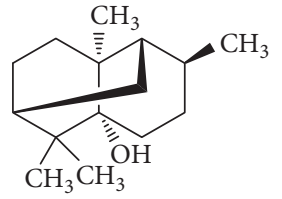

1<smiles>C=C[C](C)CCO</smiles><smiles>C=C(C)C1CC=C(C)C(=O)C1</smiles>

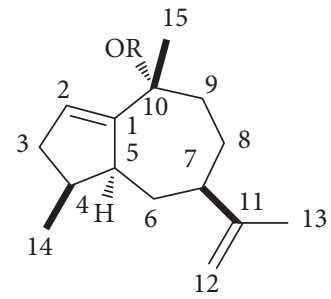

12: $\mathrm{R}=\mathrm{OH}$

12a: $\mathrm{R}=\mathrm{OH}$<smiles>OC(C#CC#CC(O)(c1ccccc1)c1ccccc1)(c1ccccc1)c1ccccc1</smiles>

2<smiles>CC1=CC=CC(C)(C)C1=O</smiles>

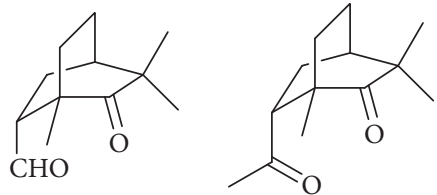

6

7<smiles>CC12CCC(CC1O)C(CO)C2</smiles>

10

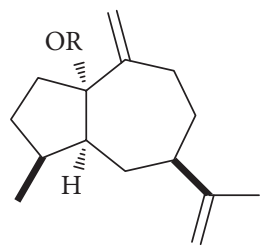

13: $\mathrm{R}=\mathrm{OH}$

13a: $\mathrm{R}=\mathrm{OH}$

14: $\mathrm{R}=\mathrm{OH}$

14a: $\mathrm{R}=\mathrm{OH}$

Scheme 1

like CNKI (http://www.cnki.net/), CBM (http://www.sinomed.ac.cn/zh/), PubMed (https://www.ncbi.nlm.nih.gov/ pubmed/), Reaxys (http://www.reaxys.com/), ACS (http:// pubs.acs.org/), EMBASE (https://www.embase.com/), and HighWire (http://home.highwire.org/). And the important compounds given were listed in Scheme 1.

\section{Availability}

2.1. Plant Sources. In nature, PA primarily exists in volatile oil of Pogostemon cablin and its contents are about 48.8\% [4]. In general, PA contents were higher in the leaves than that in the root and/or stem and altered in different collection parts as well as harvest times. As the determined technology developed, the PA was also detected within volatile oil from other plants, such as Herba Lysimachia paridiformis (22.54\%) [5], Rhizoma Valeriana jatamansi jones (5.88\%) [6], Rhizoma Nardostachys chinensis (4.5\%) [7], Radix Mallotus apelta (4.48\%) [8], Foliage Ficus microcarpa (4.05\%) [9], Herba Pholidota cantonensis (3.60\%) [10], Herba Asarum sieboldii (2.75\%) [11], Herba Gendarussa vulgaris (2.68\%)
[12], Radix Helleborus thibetanus (0.811\%) [13], Herba Sedum sarmentosum (0.53\%) [14], Aquilaria agallocha (0.392\%) [15], Pericardium Citri reticulatae (China: Xinhui, $0.178 \%$; Guangxi, 0.162\%; and Fujian, 0.086\%) [16], Fructus Periploca forrestii Schltr. (MAE, 0.12\%; and SDE, 6012\%) [17], and Foliage Microtoena patchouli [18].

To date, the PA extraction, isolation, and purification from patchouli oil mostly has depended on the combination of silica gel column chromatography and organic solvents participation. On the basis of that, Chen et al. [19] found that using molecular distillation, under the most appropriate conditions (evaporation temperature, $65^{\circ} \mathrm{C}$; feeding speed, $120 \mathrm{~mL} / \mathrm{h}$; and scraping membrane rate, $150 \mathrm{r} / \mathrm{min}$ ), raised mass fraction and extraction rate of PA. Qiu et al. [20] observed that employment of supercritical $\mathrm{CO}_{2}$ extraction (22 $\mathrm{MPa}$ of pressure, $40^{\circ} \mathrm{C}$ of temperature, and $0.07 \mathrm{~mL} / \mathrm{min}$ of flow of modifier) optimized by response surface methodology made the yield of PA up to $1.88 \%$. In addition, microwave radiation-accelerated ionic liquid pretreatment (MRAILP) was capable of enhancing extraction of patchouli alcohol (yield, 1.94\%) from Pogostemon cablin [21]. Furthermore, Li et 
al. [22] exploited a simple and rapid method for the isolation and purity of PA (yield, 6.28\%) by crystalline inclusion of using 1,1,6,6-tetraphenylhexa-2,4-diyne-1,6-diol 2. It was worth noting that a rectification-crystallization method was provided for extraction and isolation of PA from patchouli without any organic solvent, and the purity and yield reached $99 \%$ and 50\%, respectively [23], which was hopefully applied to augment large-scale industrial production.

2.2. Chemical Synthesis. Early chemical approach to synthesize PA was through Diels-Alder reaction from the known 2,6,6-trimethyl-2,4-cyclohexadien-1-one 3 and 3-methylpent-4-en-1-ol 4 [24]. Magee et al. [25] utilized a 6-exp-trig vinyl radical cyclization methodology to effect six-membered ring closure and then to acquire the desired tricyclic skeleton. Kaliappan and Subba Rao [26] obtained PA by preparing two key intermediates, 6-endo-formyl-1,3,3trimethylbicyclo[2.2.2] octan-2-one 6 and 6-endo-acetyl1,3,3-trimethylbicyclo[2.2.2] octan-2-one 7 from 2-methylbenzoic acid 5, associated with Birch reduction, Diels-Alder reaction, and catalytic hydrogenation. Moreover, Srikrishna and Satyanarayana [27] synthesized PA from the readily available monoterpene (R)-carvone $\mathbf{8}$ through tandem double Michael reaction-alkylation sequence and single electron mediated 6-endo trig cyclization reaction. Recently, the characteristic of allylic substitution of esters derived from 2-bromocyclohex-2-enol 9 with $\mathrm{PhMgBr}$-based copper reagent has been testified to afford the anti SN2 ${ }^{\prime}$ products in good yields and with sufficient chirality transfer for synthesis of PA [28].

\section{Pharmaceutics}

Researches made many beneficial tries to improve the oral bioavailability owning to the poor low water solubility of PA in gastrointestinal fluids. PA solid dispersions (SD) formulated with Eudragit were found to result in solution with the highest extent of supersaturation in addition to that the highest concentration of supersaturation of PA was maintained for prolonged time in the PA-SD with Eudragit (E-SD (1/3)) [39]. Liao et al. [40] verified the possibility using poloxamers (188 and 407) as solubility and dissolution rate enhancing agents of PA and suggested that the process of PA-SD pellets preparation was simple, rapid, cost effective, uncomplicated, and potentially scalable. Moreover, there was a communication on improving stability and dissolution rates of PA by complexing with $\beta$-cyclodextrin, which was confirmed by differential scanning calorimetry (DSC), Fourier transformation-infrared (FT-IR) spectroscopy, powder Xray diffraction (PXRD), and scanning electron microscope (SEM), respectively [41]. These efforts unambiguously could be an extremely inspiration of PA in pharmaceutical industry and medical practices.

\section{Security}

Acute toxicity investigation, referring to toxic reaction evaluation of animal by single administration or multiply accumulative administration within $24 \mathrm{~h}$, is the first step to assess drug safety. The acute toxicity experiment of PA dissolved by $0.5 \% \mathrm{CMC}-\mathrm{Na}$ in mice was performed early by Ren et al. [42]. After oral and intragastric administration of PA at the maximal dose $(0.3115 \mathrm{~g} / \mathrm{mL})$ and volume $(0.4 \mathrm{~mL} / 10 \mathrm{~g})$ for consecutive $14 \mathrm{~d}$, it gave the maximal tolerance dose of $12.5 \mathrm{~g} / \mathrm{Kg}$. Due to the limitation of PA solubility, the $\mathrm{LD}_{50}$ values could not be calculated. He et al. [43] also studying acute toxicity of PA which was dissolved with peanut oil in mice concluded $\mathrm{LD}_{50}$ values of $4.693 \mathrm{~g} / \mathrm{Kg}$ and $3.145 \mathrm{~g} / \mathrm{Kg}$ by intragastric and intraperitoneal injection administration, respectively, and PA thereby was identified to be a low toxic drug. But more preclinical studies, like long-term toxicity, special toxicity, allergy, stimulation, and so forth, on safe assessments of PA were warranted.

\section{Pharmacokinetics}

PA in pharmacokinetics was validated to be in accordance with two-compartment open model and linear kinetics elimination. After intravenous administration of PA $(10,20$, and $40 \mathrm{mg} \cdot \mathrm{Kg}^{-1}$ ) to rats, the pharmacokinetic parameters $T_{1 / 2} \beta$, AUC, and MRT examined by capillary gas chromatographic method were $36.8 \mathrm{~min}, 36534.3 \mu \mathrm{g} \cdot \mathrm{min} \cdot \mathrm{L}^{-1}$, and $34.1 \mathrm{~min}$, respectively [44]. Zhang et al. [45] developed a GC-MS assay for the determination of PA in plasma., with the mean $\mathrm{AUC}_{0-t}$ of $6916.12 \mathrm{ng} \cdot \mathrm{mL}^{-1} \cdot \mathrm{h}^{-1}, \mathrm{AUC}_{0-\infty}$ of $7896.39 \mathrm{ng} \cdot \mathrm{mL}^{-1} \cdot \mathrm{h}^{-1}$, $\mathrm{MRT}_{0-t}$ of $13.93 \mathrm{~h}, \mathrm{MRT}_{0-\infty}$ of $24.33 \mathrm{~h}, t_{1 / 2 z}$ of $19.05, T_{\text {max }}$ of $1.04 \mathrm{~h}, V_{z} / F$ of $36.31 \mathrm{~L}, \mathrm{Cl}_{z} / F$ of $1.36 \mathrm{~L} \cdot \mathrm{h}^{-1}$, and $C_{\max }$ of $545.07 \mathrm{ng} \cdot \mathrm{mL}^{-1}$ when the rats were orally gavaged with graded doses of PA $\left(10,30\right.$, and $\left.100 \mathrm{mg} \cdot \mathrm{Kg}^{-1}\right)$. Besides, oral administration of PA self-microemulsion (consists of polyoxyethylated castor oil, tween 80 , purple glycol 400, isopropyl myristate, and PA at the ratio of $2: 2: 0.8: 1.95: 0.65$, resp.) could remarkably augment AUC values in rats as compared to simple PA [46], suggesting that self-microemulsifying system was in flavor of increasing oral bioavailability of PA. As for metabolism, two hydroxylation metabolites 10-11 were obtained in liver of rabbits which were treated with PA by intraperitoneal injection [47].

\section{Pharmacological Activities}

6.1. Immunomodulatory Activities. Immune system is involved in the etiology and pathophysiological mechanisms of various diseases, and its roles have become more and more important in illuminating the mechanisms for diseases prevention and treatment [48]. Immunomodulation, either by immune increment [49] or by suppression [50], is thought to be an effectively therapeutic strategy to aid in alleviating and even curing diseases [51]. One study indicated that oral administration of PA could enhance phagocytic capability and improve immune organs thymus as well as spleen index and circulating serum IgM and IgG levels. Meanwhile, PA at the dose of $20 \mathrm{mg} / \mathrm{Kg}$ significantly repressed delayed type hypersensitivity reaction induced by 2,4-dinitrochlorobenzene in Kunming mice [52]. In other words, PA exerted appreciated immunomodulatory actions through activating mononuclear phagocytic system, augmenting humoral immune responses, and suppressing cellular immune responses, meaning that PA has a broader prospect used as an immunomodulatory agent served for clinic. 
6.2. Anti-Inflammatory Activities. In vitro test, the increased productions of TNF- $\alpha$, IL- $1 \beta$, IL- $6, \mathrm{PGE}_{2}$, and $\mathrm{NO}$ and mRNA expressions of TNF- $\alpha$, IL- $1 \beta$, IL- 6 , iNOS, and Cox2 in RAW264.7 cells (a mouse macrophages cell line) stimulated by lipopolysaccharide (LPS) which was endotoxin from Germ negative bacteria were reversed after pretreatment with PA at the concentrations of $10 \mu \mathrm{M}, 20 \mu \mathrm{M}$, or $40 \mu \mathrm{M}$ [53]. Similarly, the in vivo study on anti-inflammation of PA was conducted by Li et al. [54] and oral administration of PA $(10,20$, and $40 \mathrm{mg} / \mathrm{Kg})$ could remarkably relieve xyleneinduced ear edema in mice as well as carrageenan-induced paw edema in rats, with the reduction of inflammatory mediators release as stated above. Furthermore, PA reflecting clearly anti-inflammatory effects was performed in LPSinduced acute lung injury (ALI) $[55,56]$ as well as mastitis [57]. The mechanisms were related to the inhibition of phosphorylation of $\mathrm{I} \kappa \mathrm{B}-\alpha$ - and p65-dependent NF- $\kappa \mathrm{B}$ transcription activation, thus making it a potential efficiency for the prevention and treatment of inflammatory diseases, like ALI and mastitis. Moreover, Jeong et al. [58] suggested that, in LPS-stimulated RAW264.7 and TNF- $\alpha$-stimulated HT-29 cells (human colorectal adenocarcinoma), PA abated inflammatory responses through suppressing ERK-mediated $\mathrm{NF}-\kappa \mathrm{B}$ signaling pathway activation.

6.3. Antitumor Activities. PA was proved to have marked antitumor abilities against HCT116 and SW480 (human colorectal cancer cells), MCF-7 (human breast cancer cells), BxPC3 (pancreatic cancer cells), and PC3 (human prostate cancer cells), when compared with that acting in HUVEC (human umbilical vein endothelial cells). Also, it was evidenced that PA arrested cell growth and promoted apoptosis in cultured HCT116 and SW480 and thus PA was regarded as cancer specific [59]. In the molecular basis, PA downregulated HDAC2 expression, which consequently attenuated cmyc expression, triggering p21 expression and suppressing cyclin D1 together with CDK4, and activated upon p65dependent $\mathrm{NF}-\kappa \mathrm{B}$ transcription. In here, the regulation of NF- $\kappa \mathrm{B}$ signaling pathway in response to PA in human colorectal cancer cells was different in TNF- $\alpha$-stimulated HT-29 cells. However, the dual effects of anticancer drug aspirin, similar to PA, also described in other studies, and the mechanisms were attributed to the inhibition of IKK activity and $\mathrm{I} \kappa \mathrm{B}-\alpha$ degradation [60-62]. As for the effects on human androgen independent prostate cancer cells (DU145), Cai et al. observed that PA treatment $(10 \mathrm{mg} / \mathrm{L}$ to $160 \mathrm{mg} / \mathrm{L})$ not only blocked its cell proliferation detected by MTT but also led to alternation of morphological as well as biochemical features of apoptosis and further elucidated the pathway by which PA induced apoptosis via triggering dissipation of mitochondrial membrane potential after elevating the ratio of $\mathrm{Bax} / \mathrm{Bcl}-2$, releasing cytochrome $\mathrm{c}$ to the cytosol following the activation of caspase-3, and repressing livin protein expression [63].

6.4. Antioxidative Activities. PA was exhibited to have antioxidative activities as follows: (I) PA could block the malondialdehyde (MDA) formation from squalene on UV irradiation by $28.8 \%$, in the thiobarbituric acid assay [64]. (II) As an in vitro study, Liu et al. demonstrated that PA reversed heat stress-stimulated Keap 1 and HO-1 mRNA expressions promotion in cultured IEC-6 (rat intestinal epithelial cell), and the modulatory effects of PA on injured cell by oxidative stress were superior to that of glutamine [65]. (III) Considering that inflammation and oxidative injury interacted with each other, both anti-inflammatory and antioxidative activities of PA were investigated in UV radiation-induced cutaneous photoaging mice [66] and in ethanol, indomethacin, and stress-induced ulcer rats [67]. These results displayed that, except the regulation of inflammatory mediators, oral administration of PA $(10,20$, and $40 \mathrm{mg} / \mathrm{Kg})$ also enhanced the activities of SOD, GSH-Px, and CAT, which scavenged ROS by catalyzing them into $\mathrm{O}_{2}$ and $\mathrm{H}_{2} \mathrm{O}$ [68], and lowered the contents of MDA, suggesting that PA may be used as a promising reagent served for photoaging and gastric ulcer.

Besides, in the process of screening high throughput drug of estrogen receptor $\beta(\mathrm{ER} \beta)$ agonist by established gene report technology, PA was identified to specifically agonize $\mathrm{ER} \beta$ which was known to protect nerve from toxicity and to ameliorate animals' learn and cognitive functions. Huang et al. [69] researched the effect of PA on scopolamine-induced memory impairment in mice and found PA treatment for consecutive $10 \mathrm{~d}$ could significantly improve the abilities of learn and memory, with the inhibition of AchE activities in the brain, and the elevation of chat activities and M1 receptor levels; in addition to that PA could prevent $\mathrm{A} \beta_{25 \sim 35^{-}}$ induced neuronal apoptotic death through $\mathrm{Ca}^{2+}$ load and ROS generation. Thereby, it is possible that PA was explored as novel natural drug against Alzheimer's disease [70].

6.5. Antimicrobial Activities. Microbes, also called pathogenic microorganisms, which invade the host, may eventually result in the occurrence of infectious [71] and allergic diseases [72], even the death [73]. At present, the abuse of antibiotics and chemotherapeutic agents has made the pathogens fail to respond to treatment and show drug resistance. Because of no obvious side effects, natural products have received more attentions as antipathogenic microorganism agents for the treatment to drug-resistant pathogenic microorganisms in recent years. PA, one of nature compounds, exhibited directly inhibitory or zapped effects on various pathogens including bacteria, viruses, and fungus, which was listed in Table 1, numbers 1-16.

6.5.1. Antibacterial Activities. The antibacterial activities of patchouli oil were studied by using feasible molecular docking technology and in vitro antibacterial test [29], and the study revealed that, among the 31 chemical compounds, PA was confirmed to be the main principle of patchouli oil in exerting strongly antibacterial potential against $E$. coli, P. aeruginosa, B. proteus, S. dysenteriae, T. bacillus, and $S$. aureus. Additionally, PA showed selective antibacterial activities against in vitro $H$. pylori without affecting the normal flora of gastrointestinal tract, and its anti- $H$. pylori effect was greater than that of amoxicillin with MIC value of $78 \mu \mathrm{g} / \mathrm{mL}$ and $120 \mu \mathrm{g} / \mathrm{mL}$, respectively [30]. Due to its potently inhibitory abilities to urease, thereby, PA can be regarded as a promising agent to cure specific $H$. pylori infection. 
TABLE 1: The list of antimicrobial and insecticidal activity of PA.

\begin{tabular}{|c|c|c|c|c|}
\hline Numbers & Tested mode & Tested subject & $\begin{array}{c}\text { Parameters } \\
\left(\mathrm{MIC} / \mathrm{IC}_{50} / \mathrm{LD}_{50} / \mathrm{MLC}\right)\end{array}$ & References \\
\hline \multicolumn{5}{|c|}{ Bacteria } \\
\hline 1 & In vitro & E. coli & $\mathrm{MIC}=1.0 \mathrm{mg} / \mathrm{mL}$ & {$[29]$} \\
\hline 2 & In vitro & P. aeruginosa & $\mathrm{MIC}=3.5 \mathrm{mg} / \mathrm{mL}$ & [29] \\
\hline 3 & In vitro & B. proteus & $\mathrm{MIC}=3.5 \mathrm{mg} / \mathrm{mL}$ & [29] \\
\hline 4 & In vitro & S. dysenteriae & $\mathrm{MIC}=3.0 \mathrm{mg} / \mathrm{mL}$ & [29] \\
\hline 5 & In vitro & T. bacillus & $\mathrm{MIC}=6.5 \mathrm{mg} / \mathrm{mL}$ & [29] \\
\hline 6 & In vitro & S. aureus & $\mathrm{MIC}=2.0 \mathrm{mg} / \mathrm{mL}$ & [29] \\
\hline 7 & In vitro & H. pylori & $\mathrm{MIC}=78 \mu \mathrm{g} / \mathrm{mL}$ & {$[30]$} \\
\hline \multicolumn{5}{|c|}{ Viruses } \\
\hline 8 & In vitro & $\mathrm{A} / \mathrm{PR} / 8 / 34(\mathrm{H} 1 \mathrm{~N} 1)$ & $\mathrm{IC}_{50}=2.635 \mu \mathrm{M}$ & {$[31]$} \\
\hline 9 & In vitro & $\mathrm{B} / \mathrm{Ibaraki} / 2 / 85$ & $\mathrm{IC}_{50}=40.82 \mu \mathrm{M}$ & {$[31]$} \\
\hline 10 & In vivo & A/Leningrad/134/17/1957 (H2N2) infection mice & - & [32] \\
\hline 11 & In vitro & A/Leningrad/134/17/1957 (H2N2) & $\mathrm{IC}_{50}=4.03 \mu \mathrm{M}$ & {$[32]$} \\
\hline 12 & In vivo & A/FM1/1/47 (H1N1) infection mice & - & [33] \\
\hline 13 & In vitro & A/FM1/1/47 (H1N1) infection 16HBE & - & [34] \\
\hline \multicolumn{5}{|c|}{ Fungus } \\
\hline 14 & In vitro & A. flavus (3.2758) & - & [35] \\
\hline 15 & In vitro & A. flavus (3.4408) & - & {$[35]$} \\
\hline 16 & In vitro & Aspergillus oryzae & - & {$[35]$} \\
\hline \multicolumn{5}{|c|}{ Termite } \\
\hline 17 & In vivo & Coptotermes formosanus Shiraki & $\mathrm{LD}_{50}=4.57 \mu \mathrm{g} /$ termite & {$[36]$} \\
\hline \multicolumn{5}{|c|}{ Mosquitoes } \\
\hline 18 & In vivo & Ae. aegypti & - & [37] \\
\hline 19 & In vivo & An. stephensi & - & {$[37]$} \\
\hline 20 & In vivo & Cx. quinquefasciatus & - & [37] \\
\hline \multicolumn{5}{|c|}{ Trypanosoma } \\
\hline 21 & In vivo & Trypanosoma cruzi & $\mathrm{MLC}>200 \mu \mathrm{M}$ & {$[38]$} \\
\hline
\end{tabular}

MIC, minimal inhibition concentration; $\mathrm{IC}_{50}, 50 \%$ of lethal concentration; $\mathrm{LD}_{50}, 50 \%$ of lethal dose; $\mathrm{MLC}$, minimal lethal concentration.

6.5.2. Antiviral Activities. Concerning the assessment of in vitro anti-influenza virus (IFV) A/PR/8/34 (H1N1), it was showed that PA, at the concentrations of $2 \mu \mathrm{g} / \mathrm{L}$ and $10 \mu \mathrm{g} / \mathrm{L}$, reduced the population of plaque by $75 \%$ and $89 \%$, respectively, with $\mathrm{IC}_{50}$ of $2.635 \mu \mathrm{M}$ [31]. Similarly, the results presented by Wu et al. [32] were proved to be that anti-IFV strain A/Leningrad/134/17/1957 (H2N2) of PA with $\mathrm{IC}_{50}$ of $4.03 \mu \mathrm{M}$ and suggested that the support of PA used in H2N2-elicited infection was related to interference of PA with in silico NA activities through stabilization by binding NA invariant key active-site residues Asp151, Arg152, Glu119, Glu276, and Tyr406. The in vivo anti-IFV activity of PA was studied as well and the study disclosed oral administration of PA $(20 \mathrm{mg} / \mathrm{Kg}$ to $80 \mathrm{mg} / \mathrm{Kg}$ ) would be able to augment protection against influenza viral infection mice by increasing CD3+ and CD4+ T cell levels as well as the CD4+/CD8+ ratio, and anti-IFV IgA, IgM, and IgG titers productions to enhance the host immune responses and by restraining TNF- $\alpha$, IL- 4 , and IFN- $\gamma$ inflammatory factors release to attenuate systemic and pulmonary inflammatory responses [33]. Moreover, Wu et al. [34] investigated the interference of PA in infectious $16 \mathrm{HBE}$ (human respiratory epithelial cell) by A/FM1/1/47 (H1N1) and found PA could evoke the abilities of natural immune recognition and responses but attenuate the inflammatory responses through repressing the IFN- $\gamma$ expression.

6.5.3. Antifungal Activities. The mediate (43.62 ppm) and highest concentrations (65.42 ppm) of PA were showed to have antifungal activities against all tested fungi, including A. flavus (3.2758), A. flavus (3.4408), and A. oryzae, at either low (0.95) or high (0.98) $a_{w}$ (water activity) level, via reducing colony growth rate, which represented a available solution for possible application of PA in the food industry [35]. Besides, Mirko et al. [74] found that PA could inhibit the asexual propagation of fungi and prevent the adhesion of microorganisms to surfaces, and therefore PA was recommended to be used in life household, like filter media, adhesives, building materials, building auxiliaries, laundry detergents, cleaning compositions, rinse agents, fabric treatment compositions, hand washing compositions, manual dishwashing detergents, machine dishwashing detergents, cosmetic compositions, 


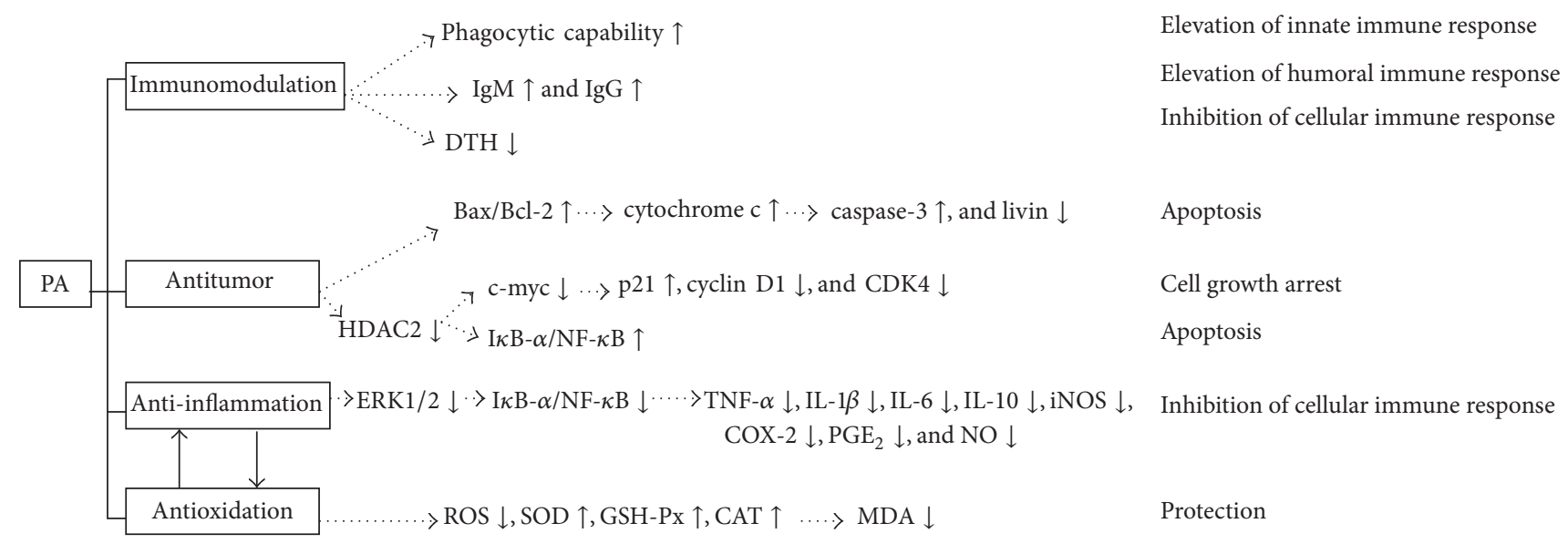

FIGURE 1: Possible mechanisms of bioactivities of PA in immunomodulation, antitumor, anti-inflammation, and antioxidation. Arrow up denotes activation or increase; arrow down denotes suppression or decrease. Inflammation and oxidation interact with each other.

pharmaceutical compositions, oral hygiene compositions, dental care compositions, and denture care compositions.

6.6. Insecticidal Activities. The experiment on repellent and toxic effects of PA on Coptotermes formosanus Shiraki (Isoptera: Rhinotermitidae) was carried out by $\mathrm{Zhu}$ et al. [36]. The results uncovered that PA pretreatment resulted in elevation in mortality percentage and decline in termites feeding, contacting and tunneling behaviors, and particularly the internal tissue of termites was destructed inside the exoskeleton when PA was topically applied into the dorsum (Table 1, number 17). Furthermore, PA was witnessed to have obvious repellency and toxicity towards mosquitoes (Table 1 , numbers $18-20)$. PA, at $2 \mathrm{mg} / \mathrm{cm}^{2}$ concentration, was the most effective for repellent activity, providing $100 \%$ protection up to $280 \mathrm{~min}$, against Ae aegypti, An. Stephensi, and Cx. quinquefasciatus, and for pupicidal activity at $100 \mathrm{mg} / \mathrm{L}$ concentration, providing 28.44, 26.28, and 25.36 against above vector mosquitoes tested [37]. These findings provide experimental basis for the development of PA as an ideal ecofriendly pesticide for the control of termites and mosquitoes.

There was another published paper where three new sesquiterpene hydroperoxides 12-14 isolated from acetone extract of Pogostemonis Herba exhibited potent trypanocidal activities, and the MLC values were estimated to be $0.84 \mu \mathrm{M}$, $1.7 \mu \mathrm{M}$, and $1.7 \mu \mathrm{M}$, respectively, when compared with that of a known sesquiterpene patchouli alcohol (MLC > $200 \mu \mathrm{M})$ (Table 1, number 21). It suggests that it is operational to improve the trypanocidal actions by appropriate structural modification of PA [38].

6.7. Antiatherogenic Activities. The study using atherosclerosis-prone apolipoprotein E knockout mice was carried out by Wang et al. [75] who demonstrated PA had antiatherogenic actions through attenuating atherosclerotic plaque burdens in both the aorta and the aortic root, reducing macrophage infiltration, and repressing inflammatory response via downregulation of MCP-1, iNOS, IL-1b, IL-6, CXCL9, and CXCL11 expressions.
6.8. Antiemetic Activities. Yang et al. [76] observed that treatment of young chickens with $50 \mathrm{mg} / \mathrm{Kg}$ and $70 \mathrm{mg} / \mathrm{Kg}$ of PA lowered excessive contractions of digestive organ smooth muscles by reducing extracellular $\mathrm{Ca}^{2+}$ influx, verifying PA in Pogostemonis Herba may play a pivotal role in antiemetic effects clinically in view of utilization of TCM.

6.9. Whitening Activities. In B16 melanoma cells, PA treatment could inhibit melanin synthesis in a dose-dependent manner $\left(\mathrm{IC}_{50}=3.9 \mu \mathrm{g} / \mathrm{mL}\right)$, weaken ROS scavenging activities in $\mathrm{DPPH}$ radical $\left(\mathrm{IC}_{50}=3.14 \pm 0.12 \mu \mathrm{g} / \mathrm{mL}\right)$ and xanthine/xanthine oxidase system $\left(\mathrm{IC}_{50}=49 \pm 3.24 \mu \mathrm{g} / \mathrm{mL}\right)$ and intracellular tyrosinase activities, and suppress tyrosinase as well as TRP-2 expressions [77], suggesting that PA could be used as a useful whitening agent.

6.10. Sedative Activities. It was reported that single inhalation administration of PA which stemmed from Microtoena patchouli presented clearly sedative effects by suppressing spontaneous motor activities [18].

\section{Conclusions}

PA is being explored and used in fragrance industries, but there is currently no report on application of PA in medical fields. This review summarizes the updated researches published on the availability, pharmaceutics, security, pharmacokinetics, and pharmacological activities of PA, which may aid in accelerating its development and medical practices, but what it chiefly needs to overcome is high cost industrial production and poor low water dissolution of PA.

The present information exhibited remarkably therapeutic properties of PA in vivo and in vitro, which could be contributed to the prevention and treatment of many diseases, such as immune disorders, infections by microbes, mosquitoes or Trypanosoma cruzi, ALI, mastitis, gastric ulcer, skin photoaging, atherosclerosis, and tumor. As shown in Figure 1, PA totally had powerful bioactivities to regulate immune functions, including immune defense, homeostasis, 
and surveillance. However, further studies are required for investigating PA which especially is how to accurately and bilaterally regulate the $\mathrm{NF}-\kappa \mathrm{B}$ nuclear transcription and the release of inflammatory factors.

Although various bioactivities of PA were authenticated using laboratory animals and cells, few molecular mechanisms of action and definite target protein bound by PA are known, in addition to limited efforts made in both the pharmacokinetic investigation related to the mechanisms of action and toxicological assessments of PA, which may severely hamper development of new drug and clinical applications of PA.

\section{Conflicts of Interest}

The authors declared that there are no conflicts of interest.

\section{Acknowledgments}

This study is supported by Key Laboratory of Standardization of Chinese Herbal Medicines of the Ministry of Education, Pharmacy College, Chengdu University of Traditional Chinese Medicine.

\section{References}

[1] Chinese Pharmacopoeia Committee, Pharmacopoeia of China, Chinese Medical Science and Technology Press, Beijing, China, 2010.

[2] L. V. Gubareva, "Molecular mechanisms of influenza virus resistance to neuraminidase inhibitors," Virus Research, vol. 103, no. 1-2, pp. 199-203, 2004.

[3] M. Kiso, K. Mitamura, Y. Sakai-Tagawa et al., "Resistant influenza A viruses in children treated with oseltamivir: descriptive study," The Lancet, vol. 364, no. 9436, pp. 759-765, 2004.

[4] L. Huang, H. Wu, G. Zhang et al., "Analysis of supercritical $\mathrm{CO}_{2}$ extraction products from Herba Pogostemonis by GCMS," Journal of Instrumental Analysis, vol. 20, no. 4, pp. 79-81, 2001.

[5] X. Zhou, G. Liang, D. Wang, and B. Xu, "Study on the chemical constituents of the volatile oil from Lysimachia trientaloides Hemsl," Chinese Journal of Chromatography, vol. 20, no. 3, pp. 286-288, 2002.

[6] H. Wang, X. Wan, X. Yan et al., "Chemical constituents of supercritical $\mathrm{CO}_{2}$ extract from Valeriana jatamansi," Journal of Beijing University of Traditional Chinese Medicine, vol. 30, no. 12, pp. 832-835, 2007.

[7] K. Tanaka and K. Komatsu, "Comparative study on volatile components of Nardostachys Rhizome," Journal of Natural Medicines, vol. 62, no. 1, pp. 112-116, 2008.

[8] J. Li, F. Chen, and Z. Lv, "Study on volatile ingredients of Mallotus apelta (Lour)," Traditional Chinese Medicine, vol. 26, no. 10, pp. 723-724, 2003.

[9] Y. Li, W. Wang, Z. Sun et al., "Study on volatile components of Foliage Ficus microcarpa," China Journal of Chinese Materia Medica, vol. 33, no. 1, pp. 87-88, 2008.

[10] K. Li, Y. Lu, X. Gu, and W. Kang, "Analysis of volatile components in the aerial parts of Pholidota cantonensis by HS-SPMEGC-MS," China Pharmacy, vol. 23, no. 35, pp. 3319-3320, 2012.
[11] S. Yuan, J. Wei, and H. Lin, "Analysis on chemical components of volatile oil of Yichang Asarum sieboldii by GC/ MS," China Journal of Chinese Materia Medica, vol. 29, no. 3, p. 280, 2004.

[12] L. Su, Y. Cai, H. Zhu, Y. Zhu, and X. Li, "Analysis on chemical components of volatile oil of Gendarussa vulgaris by GC/ MS," Journal of Guangxi Traditional Chinese Medical University, vol. 12, no. 2, pp. 56-58, 2009.

[13] Y. Gao, F. Jin, X. Wang, H. Qian, and Y. Li, "Analysis on volatile components of Helleborus thibetanus by GC/MS," Lishizhen Medicine and Materia Medical Research, vol. 22, no. 1, pp. 122123, 2011.

[14] R. Han and B. Wang, "Study on the chemical constituents of the essential oil from Sedum sarmentosum Bunge," Journal of Liaoning University of TCM, vol. 9, no. 3, pp. 73-74, 2007.

[15] H. Deng, H. Tong, and R. Zhou, "SFE- $\mathrm{CO}_{2}$ and GC-MS analysis of the essential oil from Chinese Eaglewood," West China Journal of Pharmaceutical Sciences, vol. 23, no. 6, pp. 633-635, 2008.

[16] X. Zhou, Q. Huang, S. Liao, Y. Mo, and S. Chen, "Analysis on volatile oil of Pericarpium Citri Reticulatae from different areas by GC/MS," Pharmacy Today, vol. 19, no. 4, pp. 43-45, 2009.

[17] X. Hu, X. Zhou, M. Li, H. Liu, and W. Zhou, "Analysis on chemical constituents of volatile oil of the fruit of Periploca forrestii Schltr," Journal of Instrumental Analysis, vol. 26, pp. 160$163,2007$.

[18] K. Ito and M. Ito, "Sedative effects of vapor inhalation of the essential oil of Microtoena patchoulii and its related compounds," Journal of Natural Medicines, vol. 65, no. 2, pp. 336343, 2011.

[19] H. Chen, J. Zhang, H. Zhu, and Z. Song, "Purification of patchouli alcohol in volatile oil of Pogostemon cablin by molecular distillation," Chinese Traditional and Herbal Drugs, vol. 40, no. 1, pp. 60-63, 2009.

[20] J. Qiu, Z. Wang, L. Zhou, and J. Cai, "Optimization of supercritical $\mathrm{CO}_{2}$ extraction of patchouli alcohol from Pogostemon cablin by response surface methodology," Northwest Pharmaceutical Journal, vol. 27, no. 4, pp. 309-312, 2012.

[21] L. Fan, R. Jin, Y. Liu, M. An, and S. Chen, "Enhanced extraction of patchouli alcohol from Pogostemon cablin by microwave radiation-accelerated ionic liquid pretreatment," Journal of Chromatography B: Analytical Technologies in the Biomedical and Life Sciences, vol. 879, no. 30, pp. 3653-3657, 2011.

[22] X. Li, C. Peng, Q. Zou, L. Xiong, D. Lin, and L. Guo, "Method of rapid isolation and purification of patchouli alcohol and pogostone from patchouli oil," Pharmacy and Clinics of Chinese Materia Medica, vol. 4, no. 6, pp. 4-6, 2013.

[23] X. Lai, Z. Su, and Y. Li, "A method for isolating and purifying patchouli alcohol," China: 200910193088.2, 2010.

[24] F. Näf and G. Ohloff, "A short stereoselective total synthesis of racemic patchouli alcohol. Preliminary communication," Helvetica Chimica Acta, vol. 57, no. 6, pp. 1868-1870, 1974.

[25] T. V. Magee, G. Stork, and P. Fludzinski, "A total synthesis of rac-patchouli alcohol," Tetrahedron Letters, vol. 36, no. 42, pp. 7607-7610, 1995.

[26] K. P. Kaliappan and G. S. R. Subba Rao, "Synthesis based on cyclohexadienes. Part 22. Formal syntheses of patchouli alcohol and norpatchoulenol," Journal of the Chemical Society-Perkin Transactions 1, no. 9, pp. 1385-1389, 1997.

[27] A. Srikrishna and G. Satyanarayana, "An enantiospecific total synthesis of (-)-patchouli alcohol," Tetrahedron Asymmetry, vol. 16, no. 24, pp. 3992-3997, 2005. 
[28] A. Ikoma and Y. Kobayashi, "Allylic substitution of esters derived from 2-bromocyclohex-2-enol with aryl copper reagents and synthetic utilization of the derived anti s N2/ products," Synlett, vol. 25, no. 8, pp. 1150-1154, 2014.

[29] X. Yang, X. Zhang, S.-P. Yang, and W.-Q. Liu, "Evaluation of the antibacterial activity of patchouli oil," Iranian Journal of Pharmaceutical Research, vol. 12, no. 3, pp. 307-316, 2013.

[30] X.-D. Yu, J.-H. Xie, Y.-H. Wang et al., "Selective antibacterial activity of patchouli alcohol against Helicobacter pylori based on inhibition of urease," Phytotherapy Research, vol. 29, no. 1, pp. 67-72, 2015.

[31] H. Kiyohara, C. Ichino, Y. Kawamura, T. Nagai, N. Sato, and H. Yamada, "Patchouli alcohol: in vitro direct anti-influenza virus sesquiterpene in Pogostemon cablin Benth," Journal of Natural Medicines, vol. 66, no. 1, pp. 55-61, 2012.

[32] H. Wu, B. Li, X. Wang, M. Jin, and G. Wang, "Inhibitory effect and possible mechanism of action of patchouli alcohol against influenza a (H2N2) virus," Molecules, vol. 16, no. 8, pp. 64896501, 2011.

[33] Y.-C. Li, S.-Z. Peng, H.-M. Chen et al., "Oral administration of patchouli alcohol isolated from Pogostemonis Herba augments protection against influenza viral infection in mice," International Immunopharmacology, vol. 12, no. 1, pp. 294-301, 2012.

[34] X.-L. Wu, D.-H. Ju, J. Chen et al., "Immunologic mechanism of patchouli alcohol anti-H1N1 influenza virus may through regulation of the RLH signal pathway in vitro," Current Microbiology, vol. 67, no. 4, pp. 431-436, 2013.

[35] D. Kocevski, M. Du, J. Kan, C. Jing, I. Lačanin, and H. Pavlović, "Antifungal effect of Allium tuberosum, Cinnamomum cassia, and Pogostemon cablin essential oils and their components against population of aspergillus species," Journal of Food Science, vol. 78, no. 5, pp. M731-M737, 2013.

[36] B. C.-R. Zhu, G. Henderson, Y. Yu, and R. A. Laine, "Toxicity and repellency of patchouli oil and patchouli alcohol against Formosan subterranean termites Coptotermes formosanus Shiraki (Isoptera: Rhinotermitidae)," Journal of Agricultural and Food Chemistry, vol. 51, no. 16, pp. 4585-4588, 2003.

[37] J. Gokulakrishnan, E. Kuppusamy, D. Shanmugam, A. Appavu, and K. Kaliyamoorthi, "Pupicidal and repellent activities of Pogostemon cablin essential oil chemical compounds against medically important human vector mosquitoes," Asian Pacific Journal of Tropical Disease, vol. 3, no. 1, pp. 26-31, 2013.

[38] F. Kiuchi, K. Matsuo, M. Ito, T. K. Qui, and G. Honda, "New sesquiterpene hydroperoxides with trypanocidal activity from Pogostemon cablin," Chemical and Pharmaceutical Bulletin, vol. 52, no. 12, pp. 1495-1496, 2004.

[39] Y. L. Chen, J. B. Liao, Y. Z. Liang et al., "Characterization of solid dispersions of Patchouli alcohol with different polymers: effects on the inhibition of reprecipitation and the improvement of dissolution rate," Drug Development and Industrial Pharmacy, vol. 41, no. 3, pp. 436-444, 2015.

[40] J. Liao, Y. Liang, Y. Chen et al., "Novel patchouli alcohol ternary solid dispersion pellets prepared by poloxamers," Iranian Journal of Pharmaceutical Research, vol. 14, no. 1, pp. 15-26, 2015.

[41] F. Xu, Q. Yang, L. Wu et al., "Investigation of inclusion complex of patchouli alcohol with $\beta$-cyclodextrin," PLOS ONE, vol. 12, no. 1, Article ID e0169578, 2017.

[42] S. Ren, J. Zhang, and M. Liu, "Acute toxicity of patchouli alcohol," Journal of Hainan Medical College, vol. 15, no. 12, pp. 1503-1504, 2009.
[43] J. He, S. Peng, Q. Xie et al., "Acute toxicity of patchouli alcohol," Lishizhen Medicine and Materia Medical Research, vol. 23, no. 2, pp. 274-275, 2012.

[44] F.-C. Yang, L.-Z. Xu, Z.-M. Zou, and S.-L. Yang, "Pharmacokinetics of patchouli alcohol and patchouli alcohol in patchouli oil after iv administrated to rats," Acta Pharmaceutica Sinica, vol. 39, no. 9, pp. 726-729, 2004.

[45] R. Zhang, P. Yan, Y. Li, L. Xiong, X. Gong, and C. Peng, "A pharmacokinetic study of patchouli alcohol after a single oral administration of patchouli alcohol or patchouli oil in rats," European Journal of Drug Metabolism and Pharmacokinetics, vol. 41, no. 4, pp. 441-448, 2016.

[46] X. You, R. Wang, W. Tang et al., "Micro-emulsifying system improves oral bioavailability of patchouli alcohol in rat," China Journal of Chinese Materia Medica, vol. 35, no. 6, pp. 694-698, 2010.

[47] L. Bang, G. Ourisson, and P. Teisseire, "Hydroxylation of patchoulol by rabbits. Hemi-synthesis of nor-patchoulenol, the odour carrier of patchouli Oil," Tetrahedron Letters, vol. 16, no. 26, pp. 2211-2214, 1975.

[48] S. A. Surendra and S. T. Gokul, "Bioacitivity guided isolation and characterization of the phytoconstituents from the Tridax procumbens," Brazilian Journal of Pharmacognosy, vol. 21, no. 1, pp. 58-62, 2011.

[49] B. V. Ghule, G. Murugananthan, P. D. Nakhat, and P. G. Yeole, "Immunostimulant effects of Capparis zeylanica Linn. leaves," Journal of Ethnopharmacology, vol. 108, no. 2, pp. 311-315, 2006.

[50] S. Bani, A. Kaul, B. Khan et al., "Immunosuppressive properties of an ethyl acetate fraction from Euphorbia royleana," Journal of Ethnopharmacology, vol. 99, no. 2, pp. 185-192, 2005.

[51] B. A. Bhat, K. L. Dhar, S. C. Puri et al., "Isolation, characterization and biological evaluation of datura lactones as potential immunomodulators," Bioorganic and Medicinal Chemistry, vol. 13, no. 24, pp. 6672-6677, 2005.

[52] J. B. Liao, D. W. Wu, S. Z. Peng et al., "Immunomodulatory potential of patchouli alcohol isolated from Pogostemon cablin (Blanco) Benth (Lamiaceae) in mice," Tropical Journal of Pharmaceutical Research, vol. 12, no. 4, pp. 559-565, 2013.

[53] Y.-F. Xian, Y.-C. Li, S.-P. Ip, Z.-X. Lin, X.-P. Lai, and Z.R. Su, "Anti-inflammatory effect of patchouli alcohol isolated from Pogostemonis Herba in LPS-stimulated RAW264.7 macrophages," Experimental and Therapeutic Medicine, vol. 2, no. 3, pp. 545-550, 2011.

[54] Y.-C. Li, Y.-F. Xian, S.-P. Ip et al., "Anti-inflammatory activity of patchouli alcohol isolated from Pogostemonis Herba in animal models," Fitoterapia, vol. 82, no. 8, pp. 1295-1301, 2011.

[55] Z. Su, J. Liao, Y. Liu et al., "Protective effects of patchouli alcohol isolated from Pogostemon cablin on lipopolysaccharide-induced acute lung injury in mice," Experimental and Therapeutic Medicine, vol. 11, no. 2, pp. 674-682, 2016.

[56] J.-L. Yu, X.-S. Zhang, X. Xue, and R.-M. Wang, "Patchouli alcohol protects against lipopolysaccharide-induced acute lung injury in mice," Journal of Surgical Research, vol. 194, no. 2, pp. 537-543, 2015.

[57] Y. Li, S. Yuan, G. Cai et al., "Patchouli alcohol dampens lipopolysaccharide induced mastitis in mice," Inflammation, vol. 37, no. 5, pp. 1757-1762, 2014.

[58] J. B. Jeong, Y. K. Shin, and S.-H. Lee, "Anti-inflammatory activity of patchouli alcohol in RAW264.7 and HT-29 cells," Food and Chemical Toxicology, vol. 55, pp. 229-233, 2013. 
[59] J. B. Jeong, J. Choi, Z. Lou, X. Jiang, and S.-H. Lee, "Patchouli alcohol, an essential oil of Pogostemon cablin, exhibits antitumorigenic activity in human colorectal cancer cells," International Immunopharmacology, vol. 16, no. 2, pp. 184-190, 2013.

[60] L. A. Stark, F. V. Din, R. M. Zwacka, and M. G. Dunlop, "Aspirin-induced activation of the NF- $\kappa \mathrm{B}$ signaling pathway: a novel mechanism for aspirin-mediated apoptosis in colon cancer cells," The FASEB Journal, vol. 15, no. 7, pp. 1273-1275, 2001.

[61] E. Kopp and S. Ghosh, "Inhibition of NF- $\kappa$ B by sodium salicylate and aspirin," Science, vol. 265, no. 5174, pp. 956-959, 1994.

[62] M.-J. Yin, Y. Yamamoto, and R. B. Gaynor, "The antiinflammatory agents aspirin and salicylate inhibit the activity of I $\kappa$ B kinase- $\beta$," Nature, vol. 396, no. 6706, pp. 77-80, 1998.

[63] J. Cai, C. Peng, X. Zhu et al., "Mechanism of pachouli alcohol inhibiting growth of human androgen-independent prostate cancer cell line DU145," Chinese Journal of Experimental Traditional Medical Formulae, vol. 20, no. 10, pp. 165-169, 2014.

[64] A. Wei and T. Shibamoto, "Antioxidant activities and volatile constituents of various essential oils," Journal of Agricultural and Food Chemistry, vol. 55, no. 5, pp. 1737-1742, 2007.

[65] X. Liu, S. He, L. Xu, C. Mei, F. Liu, and J. Xu, "Patchouli alcohol regulates heat stress-induce oxidative injury in IEC-6 cells," Proceedings of Chinese Association of Animal Science and Veterinary Medicine. 2014.

[66] X.-X. Feng, X.-T. Yu, W.-J. Li et al., "Effects of topical application of patchouli alcohol on the UV-induced skin photoaging in mice," European Journal of Pharmaceutical Sciences, vol. 63, pp. 113-123, 2014.

[67] Y.-F. Zheng, J.-H. Xie, Y.-F. Xu et al., “Gastroprotective effect and mechanism of patchouli alcohol against ethanol, indomethacin and stress-induced ulcer in rats," Chemico-Biological Interactions, vol. 222, pp. 27-36, 2014.

[68] J.-Y. Wong, M. A. Abdulla, J. Raman et al., "Gastroprotective effects of lion's mane mushroom Hericium erinaceus (Bull.:Fr.) Pers. (Aphyllophoromycetideae) extract against ethanolinduced ulcer in rats," Evidence-based Complementary and Alternative Medicine, vol. 2013, Article ID 492976, 2013.

[69] X. Huang, R. Liu, and Q. Lv, "The effect of patchouli alcohol on oscopolamine-induced learninand memory impairment of mice," Chinese Traditional and Herbal Drugs, vol. 40, no. 9, pp. 1431-1433, 2009.

[70] X. Huang, L. Bai, F. Xu, and Y. Wu, "Inhibitory activities of patchouli alcohol on neurotoxicity of $\beta$-amyloid Peptide," Pharmaceutical Journal of Chinese People's Liberation Army, vol. 24, no. 8, pp. 338-340, 2008.

[71] S. J. Robertson, K. Geddes, C. Maisonneuve, C. J. Streutker, and D. J. Philpott, "Resilience of the intestinal microbiota following pathogenic bacterial infection is independent of innate immunity mediated by NOD1 or NOD2," Microbes and Infection, vol. 18, no. 7-8, pp. 460-471, 2016.

[72] S. V. Lynch and H. A. Boushey, "The microbiome and development of allergic disease," Current Opinion in Allergy and Clinical Immunology, vol. 16, no. 2, pp. 165-171, 2016.

[73] Y. Zhang, X. Chen, A. Huang et al., "Mortality attributable to carbapenem-resistant Pseudomonas aeruginosa bacteremia: a meta-analysis of cohort studies," Emerging Microbes \& Infections, vol. 5, no. 3, article e27, 2016.

[74] W. Mirko, S. Anja, A. B. Bockmuehl, A. Bolte, and R. Breves, "Agents agains microorganisms containing patchouli oil, patchouli alcohol and/or the derivatives," United States: 0134239 A1, 2006.

[75] H.-T. Wang, Z.-Z. Wang, Z.-C. Wang et al., "Patchouli alcohol attenuates experimental atherosclerosis via inhibiting macrophage infiltration and its inflammatory responses," Biomedicine and Pharmacotherapy, vol. 83, pp. 930-935, 2016.

[76] Y. Yang, K. Kinoshita, K. Koyama et al., "Anti-emetic principles of Pogostemon cablin (Blanco) Benth," Phytomedicine, vol. 6, no. 2, pp. 89-93, 1999.

[77] S. Y. Bae, E. J. Lee, R. H. Son, and Y. H. Lee, “The inhibitory effects of Pogostemon cablin Bentham extract on melanogenesis," Journal of the Society of Cosmetic Scientists of Korea, vol. 35, no. 1, pp. 33-39, 2009. 


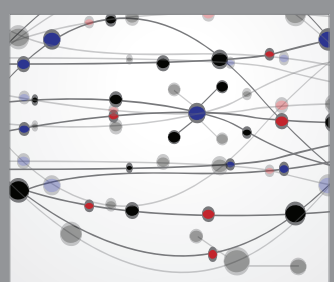

The Scientific World Journal
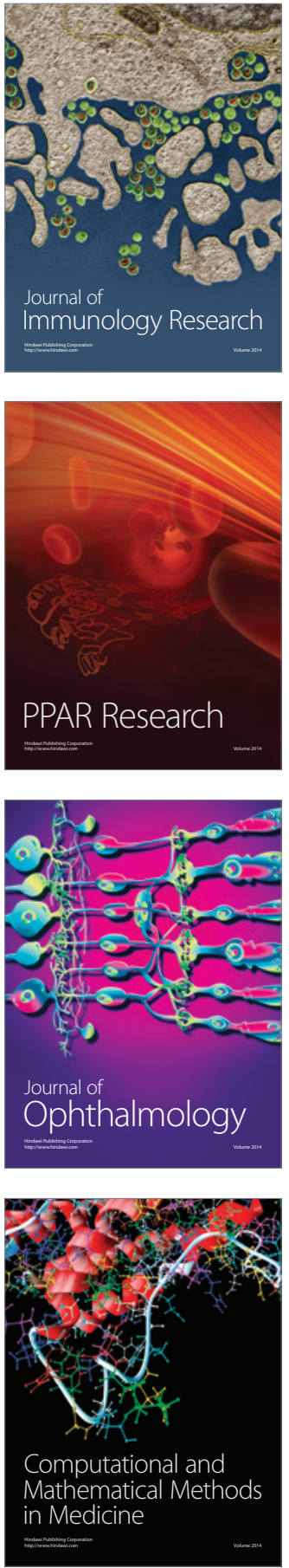

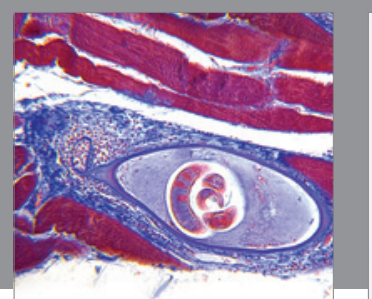

Gastroenterology Research and Practice
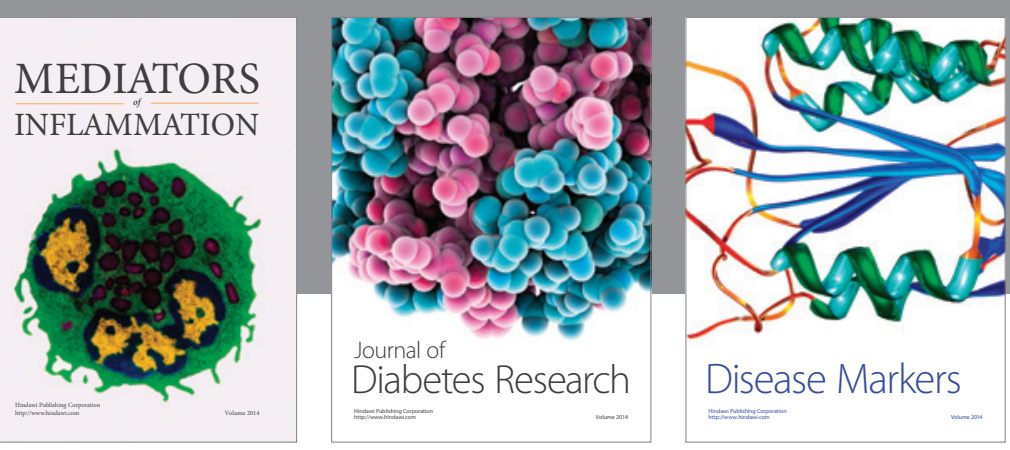

Disease Markers

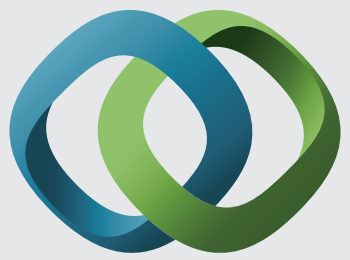

\section{Hindawi}

Submit your manuscripts at

https://www.hindawi.com
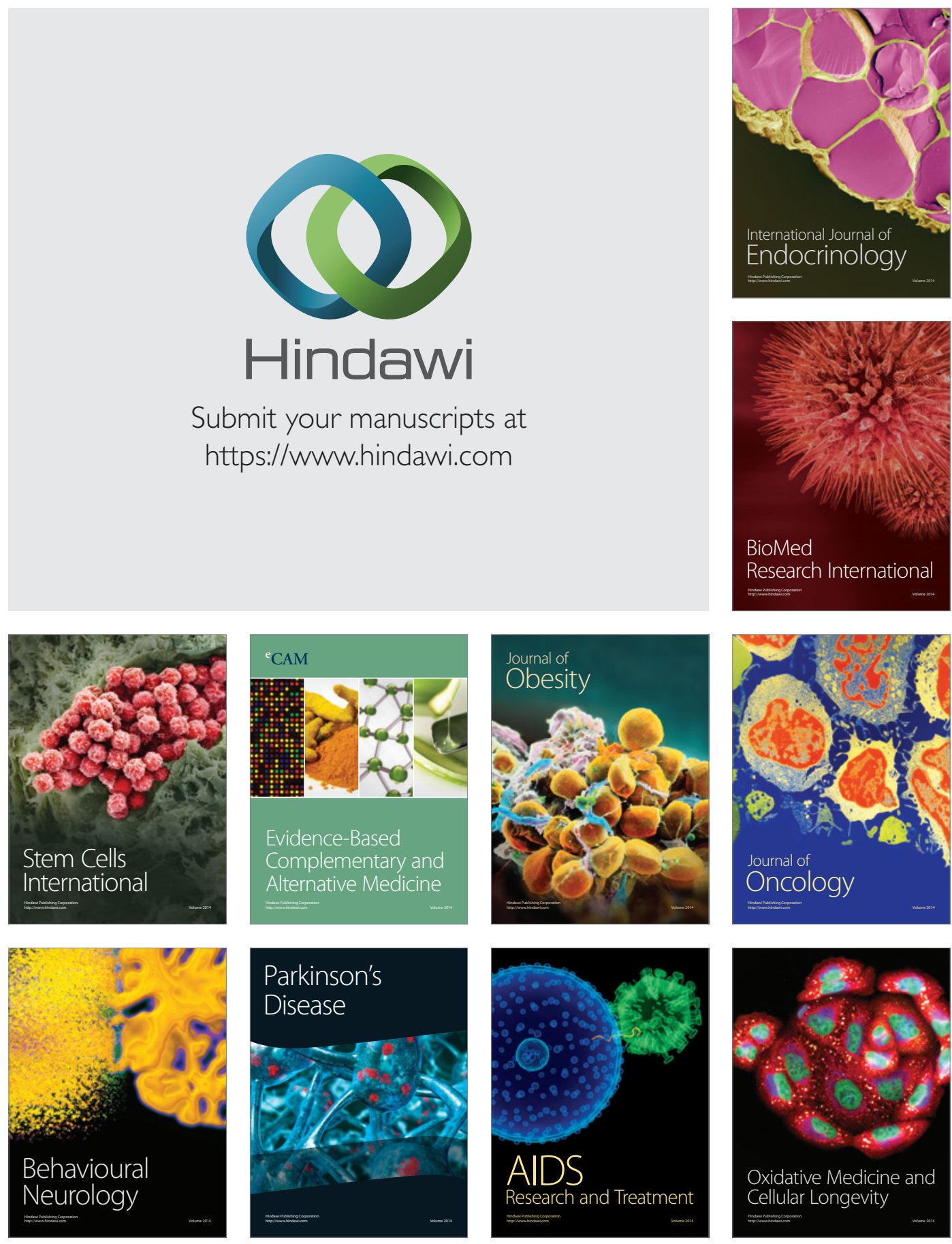